\title{
Assessing Albuminuria in Spot Morning Samples from Diabetic Patients
}

\section{original article}

\section{EMERSON SAMPAIO \\ Vinicius Daher Alvares Delfino}

Universidade Estadual de Londrina (ES); Disciplina de Nefrologia do Departamento de Clínica Médica da Universidade Estadual de Londrina (VDAD); Londrina, PR, Brasil.
Microalbuminuria assessment is essential for diagnosing incipient nephropathy in diabetic patients. The present study aim to evaluate whether urinary albumin concentration (UAC) and urinary albumin-to-creatinine ratio (UACR) agree with $24 \mathrm{~h}$ urine collection in screening for albuminuria $\geq 30 \mathrm{mg} / 24 \mathrm{~h}$ in type 1 and 2 diabetics. In this cross-sectional study were evaluated 293 diabetic patients (117 type 1 and 176 type 2). Albuminuria was determinated by turbidimetric immunoassay. The best discriminator value was $22 \mathrm{mg} / \mathrm{l}$ (sensitivity $82.5 \%$, specificity $74.0 \%$ ) for UAC and $27.3 \mathrm{mg} / \mathrm{g}$ creatinine (sensitivity $83.3 \%$, specificity $80.9 \%$ ) for UACR. Areas under ROC curves were 0.868 and 0.878 , respectively $(p=0.53$ ). Lower discriminators as $10 \mathrm{mg} / \mathrm{l}$ (sensitivity $94.2 \%$, specificity $48.6 \%$ ) and $10 \mathrm{mg} / \mathrm{g}$ creatinine (sensitivity $96.7 \%$, specificity 49.1\%) attained high sensitivities. UAC and UACR from spot morning urine had similar accuracy in screening microalbuminuria. The simplicity and lower cost of UAC justifies its preferential clinical use. (Arq Bras Endocrinol Metab 2008; 52/9:1482-1488)

Keywords: Diabetes mellitus; Diabetic nephropathy; Microalbuminuria; Spot urine sample

\section{RESUMO}

\section{Avaliação de Albuminúria em Amostra Matinal em Pacientes Diabé-} ticos.

Pesquisar microalbuminúria é essencial para o diagnóstico de nefropatia incipiente diabética. Este estudo objetiva avaliar concordância entre concentração de albumina urinária (CAU) e relação albuminúria-creatinúria (RAC) com coleta urinária de $24 \mathrm{~h}$ para pesquisa de albuminúria $\geq 30 \mathrm{mg} / 24 \mathrm{~h}$ em diabéticos tipos 1 e 2. Estudou-se transversalmente 293 pacientes diabéticos (117 tipo 1 e 176 tipo 2). A albuminúria foi determinada por imunoensaio turbidimétrico. O melhor discriminador para CAU foi $22 \mathrm{mg} / \mathrm{l}$ (sensibilidade 82,5\%, especificidade $74 \%$ ) e para RAC $27,3 \mathrm{mg} / \mathrm{g}$ de creatinina (sensibilidade $83,3 \%$, especificidade 80,9\%). Áreas sob as curvas ROC foram 0,868 e 0,878, respectivamente $(p=0,53)$. Menores discriminadores como $10 \mathrm{mg} / \mathrm{l}$ (sensibilidade $94,2 \%$, especificidade $48,6 \%$ ) e $10 \mathrm{mg} / \mathrm{g}$ de creatinina (sensibilidade $96,7 \%$, especificidade $49,1 \%$ ) resultaram sensibilidades maiores. CAU e RAC de amostras urinárias isoladas matinais apresentaram acurácia semelhante para pesquisa de microalbuminúria. Simplicidade e baixo custo da CAU justificam seu uso clínico preferencial. (Arq Bras Endocrinol Metab 2008; 52/9:14821488)

Descritores: Diabetes melito; Nefropatia diabética; Microalbuminúria; Amostra urinária isolada
Received in 30/4/2008

Acepted in 10/10/2008 


\section{INTRODUCTION}

hronic kidney disease is now recognized as a public health problem and diabetic nephropathy (DN) is the leading cause for renal replacement therapy in developed countries (1). Development of microalbuminuria is also associated with metabolic syndrome components and endothelial dysfunction and is an important risk factor for cardiovascular diseases (2). These problems are exacerbated by the increasing prevalence and longer survival of type 2 diabetes patients. Early detection of DN is essential, since interventions can delay, and possibly prevent, the development of end-stage renal disease (2).

The most important clinical marker of incipient $\mathrm{DN}$ is microalbuminuria which is characterized by persistent albuminuria in the range of 30-299 $\mathrm{mg}$ per $24 \mathrm{~h}$ (2). At the time of diagnosis, screening for microalbuminuria is recommended for type 2 diabetic patients and after five years of disease in type 1 diabetics (3). The gold standard for urinary albumin assessment is 24 $\mathrm{h}$ urine collection. Evaluating timed urine collections and albumin-to-creatinine ratio (UACR) in spot urinary samples are methods currently accepted by the American Diabetes Association (ADA) (3) and by the National Kidney Foundation (NKF) (4). Although UAC evaluation has been proposed by others (5), relationships between UAC and $24 \mathrm{~h}$ urinary collection were studied mainly in type 2 diabetics, with no or little participation from type 1 diabetes patients $(6,7)$.

The objective of our study is to evaluate whether UAC and UACR of spot urine collection agree with microalbuminuria $(\geq 30 \mathrm{mg})$ in urine collected for $24 \mathrm{~h}$ from type $\mathrm{l}$ and 2 diabetic patients in Southern Brazil.

\section{SUBJECTS AND METHODS}

Cross-sectional study of diagnostic accuracy of UAC and UACR in spot morning urine samples compared to reference standard (timed $24 \mathrm{~h}$ albuminuria).

\section{Subjects}

The study was performed in all consecutive diabetic patients $(n=478)$ attending the diabetes outpatient clinic of the Hospital at the State University of Londrina, Brazil, between May 2006 and April 2007. Patients were excluded if they were: less than 18 years old $(\mathrm{n}=$ 60 ), diagnosed with type 1 diabetes less than five years ago $(\mathrm{n}=46)$, pregnant $(\mathrm{n}=24)$, previously determined to have $24 \mathrm{~h}$ albuminuria of more than $300 \mathrm{mg}(\mathrm{n}=38)$, diagnosed with kidney disease other than $\mathrm{DN}(\mathrm{n}=4)$ or with systemic lupus erythematosus $(\mathrm{n}=8)$, and subjected to renal replacement therapy $(n=5)$. The study group consisted of 293 patients.

The study protocol was in accordance with the Helsinki Declaration and was approved by the ethics committee of the State University of Londrina; informed consent was obtained from all patients.

\section{Protocol and sample collection}

Patients were interviewed during a periodic clinical evaluation; information about age, sex, race and type of diabetes were recorded. Type 1 diabetes was defined as onset before 40 years old and insulin-dependence in the first year after diagnosis. For diabetes classification in young obese patients, clinical features, previous ketoacidosis, acanthosis nigricans and biochemical findings (plasma C-peptide, autoantibodies to insulin, glutamic acid decarboxylase and tyrosine phosphatases) were considered. Race was classified by self-reported characterization based on skin color: white, black, mixed or yellow (Japanese descendent). Weight and height were measured (anthropometer and digital balance Filizolla); body mass index (BMI) was calculated as weight in kilograms divided by the square of height in meters.

After clinical evaluation, all patients received detailed written, drawn and oral instructions about urine collection. Urine collections over $24 \mathrm{~h}$ were scheduled for the following week. No specific recommendations were made about fluid intake or diet, but patients were asked to refrain from physical exercise the day before urine collection. Patients were directed to start the 24 $\mathrm{h}$ urine collection immediately after discarding their first void of urine in the morning, and to include a final void at completion of the collection period. Between 7 and $9 \mathrm{AM}$, when patients went to the laboratory to deliver the collected urine, they were asked to collect (via the midstream technique) a fasting spot urinary sample for urinalysis, uroculture, UAC and UACR assessment. Fasting venous blood samples were taken for laboratory examination at this time. Urine collection was postponed in presence of fever $\left(>38^{\circ} \mathrm{C}\right)$, menstruation, irritated void symptoms (frequency, urgency or dysuria), macroscopic urine abnormality (cloudy urine), systolic blood pressure more than $160 \mathrm{mmHg}$ or diastolic more than $90 \mathrm{mmHg}$, cardiac failure symp- 
toms, and weight loss more than $5 \%$ in the previous three months. No patient had recent radiocontrast exposure.

\section{Laboratory analyses}

Urine volume of $24 \mathrm{~h}$ collection samples was measured by graduated chalice. Isolated urinary samples were submitted to semi-quantitative dipstick (Combur-test Multiple Reagent Strip, Roche Diagnostics, Germany) and uroculture (calibrated loop, plate growing) analyses. Urinary albumin was determinated via turbidimetric immunoassay (Cobas Mira Plus, kits by Aptec Diagnositcs, Belgium), with a low detection limit of $0.7 \mathrm{mg} / \mathrm{l}$ and sensitivity of 28.5 absorbance units/concentration unit. The intra-assay coefficient of variation $(\mathrm{CV})$ was $1.52 \%$ at $32 \mathrm{mg} / \mathrm{l}(\mathrm{n}=10)$ and $2.45 \%$ at 294 $\mathrm{mg} / \mathrm{l}(\mathrm{n}=10)$, the inter-assay $\mathrm{CV}$ was $2.93 \%$ at 32 $\mathrm{mg} / \mathrm{l}(\mathrm{n}=10)$ and $4.84 \%$ at $294 \mathrm{mg} / \mathrm{l}(\mathrm{n}=10)$. Urinary creatinine was determinated by a multi-parameter analyzer (Dimension RXL) using the Jaffé method with bichromatic measurements (kits by Dade Behring, United States). The intra-assay CV was $0.58 \%(\mathrm{n}=10)$ and inter-assay CV $0.95 \%(\mathrm{n}=10)$ at $89.6 \mathrm{mg} / \mathrm{dl}$. Glycated hemoglobin Alc ( $\mathrm{HbAlc}$ ) was determined by turbidimetric immunoassay (kits by Dade Behring, United States) with a normal range of $4.8-6.0 \%$. For cost analysis of UAC and UACR, only the kit prices for albumin and creatinine tests were taken into account.

\section{Urine collection validation}

Collections were considered incomplete and excluded if creatinine urinary excretion was less than $20 \mathrm{mg} / \mathrm{kg} / 24 \mathrm{~h}$ for males or less than $15 \mathrm{mg} / \mathrm{kg} / 24 \mathrm{~h}$ for females. For patients older than 50 years, inclusion criteria was based on the equations: [22-(age in years / 6) ] mg/kg/24 h for males, or $[22-($ age in years $/ 9)] \mathrm{mg} / \mathrm{kg} / 24 \mathrm{~h}$ or females (8). Collection was also classified as inadequate if urinalysis showed $\geq 10^{5}$ leukocytes or if uroculture resulted in $\geq 10^{5}$ organisms per milliliter. In the latter case, patients were treated with antibiotics (guided by antibiogram) before new albuminuria screening was performed. Main analyses included only validated collections.

\section{Statistical analyses}

Nominal variables were presented as percentages, the interval variables as means and standard deviations (if there was a normal distribution) or median and range (if not Gaussian). Normal distribution was tested by Kolmogorov-Smirnov one-sample $D$ statistic test. The associations between diabetes type and nominal variables (sex, race, DN diagnosis) were made by the Chisquared test; differences between means of age, BMI and $\mathrm{HbAlc}$ were evaluated by $t$ test.

Receiver Operating Characteristic (ROC) curves was calculated to compare the discriminative power of the indicators (UAC and UACR) to reference standard 9 ). The ROC curves were grouped by diabetes type and sex. The value lying nearest to the point of intersection of the ROC curve and the $100 \%$ to $100 \%$ diagonal was chosen as the best discriminator value. Sensitivity and specificity were calculated to determine the diagnostic properties of the indicators for albuminuria in general and by group. Areas under the curves were calculated and compared according to the procedure of Hanley and $\mathrm{McNeil}$ (10). The correlation was tested with Spearman's coefficient and agreement measured with inter-rater statistics (Kappa, $\kappa$ ).

Statistical analyses were performed with the statistical package MedCalc (version 8.2.0.3) and Statistica (version 6.0). Confidence intervals were 95\%, and significance was set at $\mathrm{p}=0.05$.

\section{RESULTS}

We included 293 patients, 117 type 1 and 176 type 2 diabetes, with male predominance $(59.0 \%)$ in type 1 and female $(60.8 \%)$ in type 2 group $(\mathrm{p}=0.001)$. The type 1 were younger $(31.1 \pm 9.6$ versus $58.0 \pm 12.0$, $\mathrm{p}<0.001)$, leaner $(23.4 \pm 2.3$ versus $\pm 31.1 \pm 6.8$, $\mathrm{p}<0.001$ ), and they had worse glycemic control (HbAlc $8.9 \pm 1.8$ versus $8.0 \pm 1.6, \mathrm{p}<0.001)$ than type 2 diabetes patients. There is no difference in skin color composition between the groups, with white predominance (type 1 diabetes: white $69.2 \%$, mixed $17.1 \%$, black $12.8 \%$ and yellow $0.9 \%$; type 2 diabetes: $68.2 \%, 15.3 \%$, $11.9 \%$ and $4.5 \%$ respectively, $\mathrm{p}=0.347$ ).

To obtain one validated urine collection per patient, 475 collections were necessary. There were 33 cases $(6.9 \%)$ of asymptomatic bacteriuria and 149 (31.4\%) of incomplete urine collection. It was necessary to perform $1.62 \pm 0.37$ collections to obtain one validated sample per patient; $176(60.1 \%)$ patients provided only one collection, but 117 (39.9\%) needed 2 to 5 collections. Patients under 60 years old $(n=216)$ performed a mean of $1.55 \pm 0.35$ collections and those older than 60 years $(n=77)$ provided $1.79 \pm 0.39$ collections $(\mathrm{p}<0.001)$. 


\section{Microalbuminuria detection}

In the 293 validated $24 \mathrm{~h}$ urine collections, $120(41.0 \%)$ presented with albuminuria $\geq 30 \mathrm{mg} / 24 \mathrm{~h}$; the median was $18.9 \mathrm{mg} / 24 \mathrm{~h}$ (range $<1$ to $245 \mathrm{mg} / 24 \mathrm{~h}$ ). The correlation coefficient of UAC and $24 \mathrm{~h}$ albuminuria was $r=0.70(0.64-0.76)$, similar to the coefficient of UACR and $24 \mathrm{~h}$ albuminuria with $\mathrm{r}=0.70(0.63-$ $0.75)(\mathrm{p}=0.887)$.

ROC curves for microalbuminuria analysis are presented in Figure 1. For UAC, the best discriminator value was $22 \mathrm{mg} / 1$, sensitivity was $82.5 \%(74.5-88.8 \%)$ and specificity was $74.0 \%(66.8-80.4 \%)$. For UACR, the best discriminator was $27.3 \mathrm{mg} / \mathrm{g}$ creatinine, sensitivity was $83.3 \%(75.4-89.5 \%)$ and specificity was $80.9 \%(74.3-86.5 \%)$. There was no difference between areas under UAC curve of $0.868(0.823-0.904)$ and UACR of $0.878(0.835-0.913)(\mathrm{p}=0.532)$. For best performance discriminators, the agreement coefficient $\kappa$ was 0.548 (standard error 0.058 ) for UAC and $24 \mathrm{~h}$ albuminuria; and 0.632 (standard error 0.058 ) for UACR and $24 \mathrm{~h}$ albuminuria.

The area under ROC curves and critical values for UAC and UACR as grouped by diabetes type are shown in Tables 1 and 2. There were no differences in the areas under UAC and UACR curves for type $1(0.887$ versus $0.924, \mathrm{p}=0.292)$ and type $2(0.845$ versus $0.843, \mathrm{p}=0.954$ ) diabetes; the specificities were greater in type 1 than type 2 diabetes patients. Also there were no differences in the areas under UAC and UACR

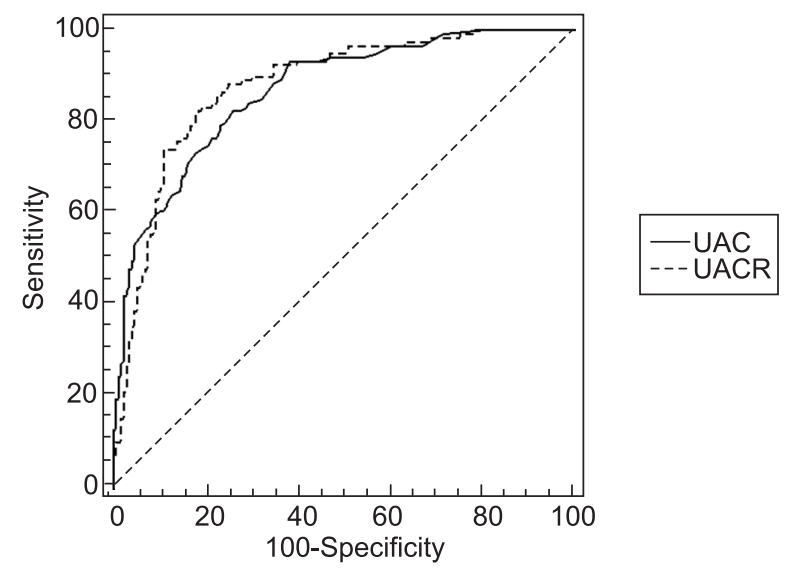

Figure 1. ROC curves for urinary albumin concentration (UAC) and urinary albumin-to-creatinine ratio (UACR) to predict microalbuminuria ( $\geq 30 \mathrm{mg} / 24 \mathrm{~h}$ ). There was no difference between areas under UAC and UACR curves $(p=0.532)$. curves for men $(0.872$ versus $0.904, \mathrm{p}=0.183)$ and women $(0.868$ versus $0.856, \mathrm{p}=0.611)$.

\section{Cost Analysis of UAC versus UACR}

Considering a 20\% population-based prevalence of DN and using the best discriminator values found in our study, microalbuminuria would be detected in 165 patients using UAC and 167 using UACR for each 1,000 patients screened. The unitary cost for UAC determination would be US $\$ 0.60$ and for UACR it would be US $\$ 0.86$. So, in this scenario, UACR would be $43 \%$ more costly than UAC, and it would detect only two more cases for every 1,000 patients screened.

\section{DISCUSSION}

Our data show that UAC and UACR of morning urine voids from type 1 and 2 diabetic patients are equally accurate in microalbuminuria screening. Our findings agree with previous studies that evaluated the usefulness of UAC and UACR in morning urinary samples compared to $24 \mathrm{~h}$ albuminuria in southern Brazilian diabetic patients $(6,7)$. Nowadays UAC method is recognized as accurate, easy to perform, and recommended by American Diabetes Association guidelines (11). However few (7) or none (6) of the patients in these Brazilian reports were type 1 diabetes patients, whereas about $40 \%$ of the total subject population were this type in our records. In our study the sensitivity of the UAC and UACR discriminators was similar in type 1 and 2 diabetes, but the specificities were greater in type 1 .

Our data did not reveal a statistical difference in UACR discriminator between genders, although this measure is expected to be gender related because women have lower muscle mass than men (12). Bakker (13) studied 2,394 diabetic patients with $12 \mathrm{~h}$ timed urine collection and proposed discriminators for UACR, but not UAC, are sex-specific.

The gold standard for assessing urinary albumin excretion is determining its levels in $24 \mathrm{~h}$ urine collection (14), since UAC follows a circadian rhythm. Diurnal variation in albuminuria is explained partly by mechanisms related to orthostasis, variation in glomerular filtration rate, serum albumin concentration and blood pressure (15).

In our study, $31 \%$ of the $24 \mathrm{~h}$ urine collections were considered incomplete and were recollected. Garde and cols. (16) reported that the typical percen- 
Table 1. Discriminator values of urinary albumin concentration (UAC) to predict microalbuminuria ( $\geq 30 \mathrm{mg} / 24 \mathrm{~h}$ ) grouped by diabetes type and sex.

\begin{tabular}{|c|c|c|c|c|c|c|}
\hline \multirow[t]{2}{*}{ Group } & \multicolumn{2}{|c|}{ Patients } & \multicolumn{4}{|c|}{ UAC } \\
\hline & Total & $+^{*}$ & $\mathrm{DV}^{\dagger}(\mathrm{mg} / \mathrm{l})$ & Sensitivity & Specificity & Area under ROC curve \\
\hline \multirow[t]{3}{*}{ All } & & & 10 & $94.2(88-97)$ & $48.6(40-56)$ & \\
\hline & 293 & 120 & 20 & $83.3(75-89)$ & $71.1(63-77)$ & $0.868(0.823-0.904)$ \\
\hline & & & 30 & $74.2(65-81)$ & $80.9(74-86)$ & \\
\hline \multirow[t]{3}{*}{ Type 1 diabetes } & & & 10 & $93.9(79-99)$ & $63.1(51-73)$ & \\
\hline & 117 & 33 & 20 & $72.7(54-86)$ & $83.3(73-90)$ & $0.887(0.815-0.938)$ \\
\hline & & & 30 & $60.6(42-77)$ & $90.5(82-95)$ & \\
\hline \multirow[t]{3}{*}{ Type 2 diabetes } & & & 10 & $94.3(87-98)$ & $34.8(25-45)$ & \\
\hline & 176 & 87 & 20 & $87.4(79-93)$ & $59.6(48-69)$ & $0.845(0.782-0.895)$ \\
\hline & & & 30 & $79.3(69-87)$ & $71.9(61-80)$ & \\
\hline
\end{tabular}

Data are reported as number of patients or as percentage and its $95 \%$ confidence interval; * albuminuria $\geq 30 \mathrm{mg}$ in $24 \mathrm{~h}$ sample. $\dagger$ DV $=$ discriminator value.

Table 2. Discriminator values of urinary albumin-to-creatinine ratio (UACR) to predict microalbuminuria ( $\geq 30 \mathrm{mg} / 24 \mathrm{~h}$ ) grouped by diabetes type and sex.

\begin{tabular}{|c|c|c|c|c|c|c|}
\hline \multirow[t]{2}{*}{ Group } & \multicolumn{2}{|c|}{ Patients } & \multicolumn{4}{|c|}{ UACR } \\
\hline & Total & $+^{*}$ & $\mathrm{DV}^{\dagger}(\mathrm{mg} / \mathrm{g} \mathrm{cr})$ & Sensitivity & Specificity & Area under ROC curve \\
\hline \multirow[t]{3}{*}{ All } & & & 10 & $96.7(92-99)$ & $49.1(41-56)$ & \\
\hline & 293 & 120 & 20 & $88.3(81-93)$ & $74.6(67-80)$ & $0.878(0.835-0.913)$ \\
\hline & & & 30 & $77.0(68-84)$ & $84.4(78-89)$ & \\
\hline \multirow[t]{3}{*}{ Type 1 diabetes } & & & 10 & $100(89-100)$ & $63.1(51-73)$ & \\
\hline & 117 & 33 & 20 & $84.8(68-94)$ & $84.5(75-91)$ & $0.924(0.860-0.964)$ \\
\hline & & & 30 & $69.7(51-84)$ & $94.0(86-98)$ & \\
\hline \multirow[t]{3}{*}{ Type 2 diabetes } & & & 10 & $95.4(88-98)$ & $37.1(27-48)$ & \\
\hline & 176 & 87 & 20 & $89.7(81-95)$ & $66.3(55-76)$ & $0.843(0.781-0.894)$ \\
\hline & & & 30 & $79.3(69-87)$ & $76.4(66-84)$ & \\
\hline
\end{tabular}

Data are reported as number of patients or as percentage and its $95 \%$ confidence interval; * albuminuria $\geq 30 \mathrm{mg}$ in $24 \mathrm{~h}$ sample. $\dagger \mathrm{DV}=$ discriminator value,

$\mathrm{cr}=$ creatinine .

tage of incomplete $24 \mathrm{~h}$ samples in non-hospitalized individuals is about 15 to $20 \%$ and Incerti and cols. (7) reported $10 \%$ of incomplete collections. However, the latter study may have underestimated the number of incomplete samples due to a smaller urinary creatinine excretion judgment. Complete urine collection may be difficult to obtain due to forgetfulness, misplaced samples, lack of container capacity, erroneous in- clusion of urine from the first void and loss of urine during defecation (16). Population features are also involved in the prevalence of incomplete collection, including the protocol and the study group of interest. The elderly are a particular group with difficulties in $24 \mathrm{~h}$ urine collection, because they may present more physical restrictions, reduced mobility and urinary incontinence. Along these lines, in our study the 
elderly needed to perform $15 \%$ more urine collections than young patients to attain complete samples.

The alternative albuminuria assessment, UAC, has the potential disadvantage of being influenced by variations in urinary flow rate. Although UACR can correct this interference through urinary creatinine concentration, adding a creatinine measure also introduces variability (17). UACR also has marked diurnal rhythms, with an amplitude comparable to albuminuria itself $(15,17)$. Collecting urine between 6 and $9 \mathrm{AM}$ is ideal for UACR since the samples correlate highly with $24 \mathrm{~h}$ albuminuria in this period (17); as does fasting UAC because nocturnal water restriction increases urinary concentration and reduces flow rate variability. In our study, accuracy of UACR compared to UAC was not significantly greater in morning urine samples; as our data was derived from samples collected between 7 to 9 AM, they can not be applied to randomly collected samples.

We found equilibrium discriminator values of 22 $\mathrm{mg} / \mathrm{l}$ for UAC and of $27.3 \mathrm{mg} / \mathrm{g}$ creatinine for UACR. These values are similar to those found by others [Zelmanovitz et al. (33.6 mg/l; $26.8 \mathrm{mg} / \mathrm{g}$ creatinine); Incerti and cols. $(29.7 \mathrm{mg} / \mathrm{l} ; 32 \mathrm{mg} / \mathrm{g}$ creatinine $)]$. The small variation in discriminator values could be due to analytic features (analytic methods, standardization) as well as procedural aspects (amount of patients, composition of patient group) (13). The ADA and NKF established a cut-off for UACR of $30 \mathrm{mg} / \mathrm{g}$ creatinine $(3,4)$ and, for UAC, the cut-off is $20 \mathrm{mg} / \mathrm{l} \mathrm{ac}-$ cording to the European Diabetes Policy Group (19). In our patients, using these cut-off criteria resulted in $23.0 \%$ false negative results for UACR and $16.7 \%$ for UAC suggesting these standards have low sensitivity for screening (20).

Since a continuous relationship exists between the level of urinary albumin excretion and clinical endpoints, as much lower values than the current cut-off of $30 \mathrm{mg} / \mathrm{d}$ are associated with risk of overt nephropathy, myocardial infarction, and cardiovascular death (21), using lower creatinine discriminator values (e.g. 10 $\mathrm{mg} / \mathrm{l}$ or $10 \mathrm{mg} / \mathrm{g}$ ) would have identified almost all of the diabetic patients with microalbuminuria as well as those with "high normal albuminuria" (14). This approach could have determined the need for more intensive metabolic and hypertensive control, as well as the adoption of other measures aimed at reducing cardiovascular mortality and renal disease progression in the patients at risk. Indeed, a cut-off value of UAC of
$11 \mathrm{mg} / \mathrm{l}$ has been proposed for albuminuria screening in a large population study (20).

A single UAC measurement is easier than 24 h urine collection and eliminates the problem of incomplete collection. Moreover, it is a cheaper test for albuminuria evaluation than UACR. Thus, we propose that UAC should be employed for microalbuminuria assessment in diabetic patients with a negative protein result in the semi-quantitative dipstick. Considering a $20 \%$ population-based prevalence of $\mathrm{DN}$, for morning urinary sample with UAC less then $10 \mathrm{mg} / \mathrm{l}$ the true negative rates are $97 \%$, and the patient may be considered normoalbuminuric. For UAC larger then $10 \mathrm{mg} / \mathrm{l}$, evaluation in new spot (UACR) or timed urine are necessary, because at least two of three abnormal tests for albuminuria measured within a six months period are required before a patient is diagnosed with incipient nephropathy (2).

In conclusion, UAC and UACR in spot morning urine samples had similar accuracy in screening microalbuminuria in type 1 and 2 diabetic patients. The simplicity and lower cost of UAC justifies its preferential clinical use.

Acknowledgment: The authors thank Dr Henriqueta G. G. de Almeida from the endocrinology department of the State University of Londrina for her helpful suggestions on this manuscript. There is no conflict of interest. No potencial conflict of interest relevant to this article was reported.

\section{REFERENCES}

1 United States Renal Data System. USRDS 2006 Annual Data Report: Atlas of End-Stage Renal Disease in the United States. Bethesda, MD, National Institutes of Health, National Institute of Diabetes and Digestive and Kidney Diseases, 2006.

2 Gross JL, Azevedo MJ, Silveiro SP, Canani LH, Caramori ML, Zelmanovitz T. Diabetic nephropathy: diagnosis, prevention, and treatment. Diabetes Care. 2005;28(1):164-76.

3 American Diabetes Association. Standards of medical care in diabetes-2008. Diabetes Care. 2008; 31 Suppl 1:S12-54.

4 Eknoyan G, Hostetter T, Bakris GL, Hebert L, Levey AS, Parving $\mathrm{HH}$, et al. Proteinuria and other markers of chronic kidney disease: a position statement of the National Kidney Foundation (NKF) and National Institute of Diabetes and Digestive and Kidney Diseases (NIDDK). Am J Kidney Dis. 2003;42(4):617-22.

5 Gross JL, Zelmanovitz T, Oliveira J, Azevedo MJ. Screening for diabetic nephropathy: is measurement of urinary albuminto-creatinine ratio worthwhile? Proposal for a simple algorithm. Diabetes Care. 1999;22(9):1599-600.

6 Zelmanovitz T, Gross JL, Oliveira JR, Paggi A, Tatsch M, Aze vedo MJ. The receiver operating characteristics curve in the evaluation of a random urine specimen as a screening test for diabetic nephropathy. Diabetes Care. 1997;20(4):516-9. 
7 Incerti J, Zelmanovitz T, Camargo JL, Gross JL, Azevedo MJ. Evaluation of tests for microalbuminuria screening in patients with diabetes. Nephrol Dial Transplant. 2005;20(11):2402-7.

8 Pollack $\mathrm{H}$. Creatinine excretion as index for estimating urinary excretion of micronutrients or their metabolic end products. Am J Clin Nutr. 1970;23(7):865-7.

9 Altman DG, Bland JM. Statistics Notes: Diagnostic tests 3: receiver operating characteristic plots. BMJ. 1994;309(6948): 188.

10 Hanley JA, McNeil BJ. The meaning and use of the area under a receiver operating characteristic (ROC) curve. Radiology. 1982;143(1):29-36.

11 American Diabetes Association. Nephropathy in diabetes: Position Statement. Diabetes Care. 2004;27 Suppl 1:S79-83.

12 Connell SJ, Hollis S, Tieszen KL, McMurray JR, Dornan TL. Gender and the clinical usefulness of the albumin: creatinine ratio. Diabet Med. 1994;11(1):32-6.

13 Bakker AJ. Detection of microalbuminuria: Receiver operating characteristic curve analysis favors albumin-to-creatinine ratio over albumin concentration. Diabetes Care. 1999;22(2):307-13.

14 de Jong PE, Curhan GC. Screening, monitoring, and treatment of albuminuria: Public health perspectives. J Am Soc Nephrol. 2006;17(8):2120-6.

15 Hansen HP, Hovind P, Jensen BR, Parving HH. Diurnal variations of glomerular filtration rate and albuminuria in diabetic nephropathy. Kidney Int. 2002;61(1):163-8.

16 Garde AH, Hansen AM, Kristiansen J, Knudsen LE. Comparison of uncertainties related to standardization of urine sam- ples with volume and creatinine concentration. Ann Occup Hyg. 2004;48(2):171-9.

17 Mogensen CE, Vestbo E, Poulsen PL, Christiansen C, Damsgaard EM, Eisjaer $\mathrm{H}$, et al. Microalbuminuria and potential confounders: a review and some observations on variability of urinary albumin excretion. Diabetes Care. 1995;18(4):572-81.

18 Koopman MG, Krediet RT, Koomen GCM, Strackee J, Arisz L. Circadian rhythm of proteinuria: consequences of the use of urinary protein:creatinine ratios. Nephrol Dial Transplant. 1989;4(1):9-14.

19 European Diabetes Policy Group. A desktop guide to type 2 diabetes. Diabet Med. 1999;46:416-730.

20 Gansevoort RT, Verhave JC, Hillege HL, Burgerhof JGM, Bakker SJL, Zeeuw D, et al; PREVEND Study Group. The validity of screening based on spot morning urine samples to detect subjects with microalbuminuria in the general population. Kidney Int. 2005;67 Suppl 94:S28-35.

21 Ruggenenti P, Remuzzi G. Time to abandon microalbuminuria? Kidney Int. 2006;70(7):1214-22.

\section{Correspondence to:}

Emerson Sampaio

Avenida das Américas, 200

86040-410 Londrina PR

E-mail: emersamp@hotmail.com 